\title{
ARTICLE
}

\section{The MRCPsych post-2015: preparing trainees and improving courses}

\author{
Jayne Greening, Erin Turner, Gareth Rees \& Caroline Winkle
}

\begin{abstract}
Jayne Greening is a consultant psychiatrist with Birmingham and Solihull Mental Health NHS Foundation Trust (BSMHFT), and Director of Medical Education and Honorary Senior Clinical Lecturer at the University of Birmingham. Erin Turner is a consultant psychiatrist with BSMHFT Early Intervention Services, Chair of the core trainee MRCPsych course in Birmingham and Senior Clinical Examiner at the University of Birmingham. She has an interest in medical education and in the introduction of innovative teaching methods to the MRCPsych course. Gareth Rees is a specialist registrar (ST6) in general adult psychiatry with BSMHFT Early Intervention Services and an Honorary Clinical Teacher on Birmingham's core trainee MRCPsych course. Caroline Winkle is a specialist registrar (ST6) in old age psychiatry in the West Midlands, currently working for Dudley and Walsall Mental Health Partnership NHS Trust. She is also Honorary Clinical Teacher for Year 1 of Birmingham's core trainee MRCPsych course.

Correspondence Dr Jayne Greening, The Uffculme Centre, Queensbridge Road, Mosely, Birmingham B13 80Y, UK. Email: jayne.greening@bsmhft.nhs.uk
\end{abstract}

a. Birmingham's core trainee MRCPsych course is not to be confused with 'The Birmingham Course', run by a commercial company.

\section{SUMMARY}

This article is aimed primarily at psychiatry trainees, MRCPsych course organisers, College tutors, educational supervisors and clinical supervisors. It describes recent changes to the MRCPsych curriculum and examinations and discusses the different approaches that educators can utilise to best help their trainees. We describe how the content of MRCPsych courses can help prepare trainees for both the written papers and the clinical assessment of skills and competencies (CASC). We discuss ways of incorporating patients and carers into course development, innovative approaches using technology to enhance learning, the role of workplace-based assessments and how international graduates may maximise their pass rate.

\section{LEARNING OBJECTIVES}

- Be aware of the structure of the MRCPsych examinations

- Appreciate the recent development of online resources to support candidates preparing to sit the MRCPsych examinations

- Be able to maximise learning opportunities for international medical graduates

\section{DECLARATION OF INTEREST}

None

Recent changes to the Royal College of Psychiatrists' Membership examinations (the MRCPsych) require adaptation of existing teaching and training for core psychiatry trainees. With the General Medical Council (GMC) now limiting the number of times that a candidate can attempt the MRCPsych, there is also growing pressure to ensure that course organisers are maximising trainees' potential to pass. Using our experiences of running an MRCPsych course for core trainees which is based in Birmingham ${ }^{\mathrm{a}}$ we discuss in this article how MRCPsych courses can best be developed to prepare trainees for the MRCPsych written papers and the clinical assessment of skills and competencies (CASC).

\section{Changes to the MRCPsych examinations}

Until recently the MRCPsych examinations consisted of three written papers and the CASC.
However, in 2012 the College's Education, Training and Standards Committee agreed to reduce the number of written papers following concerns regarding the "perception of candidate examination burden' (Burn 2014a). In April 2015, MRCPsych Papers A and B replaced Papers 1, 2 and 3. Paper A covers the scientific and theoretical basis of psychiatry and is a 3-hour examination scored out of 200; Paper B is also 3 hours in duration and includes a critical review section as well as questions pertaining to clinical topics.

Both of the written papers consist of multiple choice questions (MCQs) and extended matching items (EMIs), comprising $75 \%$ and $25 \%$ of each exam respectively. MCQs are suited to assessing factual knowledge (Schuwirth 2004a) and are useful for evaluating large groups of candidates because marking them can be standardised and automated. The style of MCQ used in the MRCPsych is the ' 1 from 5 , single best answer type' (as appears at the end of this article). This consists of a short question stem and five possible responses from which candidates are asked to select the most appropriate; one mark is awarded for each correct answer and incorrect responses are not penalised. EMIs are a variant of the MCQ in which candidates are required to select from a list of 10-20 options the most appropriate response to a question stem. EMIs are therefore more useful than MCQs in assessing application of knowledge (Schuwirth 2004a), minimising recognition effect and reducing the chance of selecting correct answers by chance (George 2003). EMIs have been cited as the 'fairest' form of written examination and are increasingly the preferred method of assessing undergraduate and postgraduate courses (McCoubrie 2004). Whether a candidate passes Papers A and B of the MRCPsych depends on how their performance compares to an absolute standard and not to other candidates (Bowie 2015). Following a requirement of the GMC, candidates are now allowed a maximum of six attempts at any one component of the examinations.

The practical component of the MRCPsych remains the CASC, in which a candidate's ability to perform clinical tasks is assessed over eight individual stations and four pairs of linked 
stations (16 stations in total). Each CASC station is internally criterion referenced and the candidate's performance is marked by an appropriately trained examiner.

\section{MRCPsych courses}

The College's core curriculum states that 'It is essential that trainees in Core Psychiatry Training attend an MRCPsych course that comprises a systematic course of lectures and/or seminars covering basic sciences and clinical topics, communication and interviewing skills' (Royal College of Psychiatrists 2010: p. 82). The standards for an MRCPsych course are explicitly stated and include the need for course content to cover the curriculum, course organisers to be given adequate time and administrative support, patient/carer involvement, and regular feedback from trainees and teachers (Burn 2014b). MRCPsych courses also have a number of functions beyond preparing trainees for the exams and ideally these should complement each other to produce higher-quality psychiatrists (Schuwirth 2004b).

There are about 30 MRCPsych courses running across the UK and they vary widely in their organisation and the number of trainees attending (Berrisford 2010). The current Dean Dr Wendy Burn and the Chief Examiner Dr Peter Bowie have instigated annual meetings of all course organisers to discuss the courses and to share good practice. The Birmingham-based MRCPsych course, for example, is organised by a remunerated consultant psychiatrist with good administrative support. Specialist trainees with an interest in medical education are appointed competitively to 'honorary clinical teacher' posts and allocated a year group for which they are responsible. Patients and carers play an important role in delivering lectures, co-facilitating workshops, providing feedback on trainees' communication skills, and meeting with the course organiser and honorary clinical teachers on a regular basis.

\section{Course content}

Owing to the resource implications of teaching about 100 trainees, Birmingham's MRCPsych course is funded by trainees' study budgets and the majority of the course content is delivered via lectures. Although a programme of lectures enables trainees working in different geographical locations to meet and engage in peer support, didactic teaching can also invoke passivity and discourage deep learning (Newbie 1986). Hence, the 3-year course has integrated small-group teaching throughout year 1 ; the learning objectives for these sessions are stated explicitly (Vassilas
2011) and their content is supported by a teaching workbook. Although the content of small-group teaching sessions is not always exam focused, the shift from teacher-centred and subject-based teaching to interactive, problem-based, studentcentred learning is recognised as an advantage in adult education (Newbie 1986).

\section{Preparing trainees for the written papers of the MRCPsych}

MRCPsych courses should prepare trainees for the written papers of the examinations by offering exam practice and ensuring that the College's curricula for core and specialist training are covered by course content (Box 1). It is therefore helpful if teachers on MRCPsych courses can supplement their lectures with a set of appropriate MCQs and EMIs.

The critical review component of MRCPsych Paper B does not readily translate into teaching by lecture format. Ideally, it should be taught via small-group teaching or in a workshop format that provides trainees with additional opportunities to put their critical appraisal knowledge and skills into practice. Journal clubs are another important teaching arena (Swift 2016, this issue).

\section{Preparing trainees for the CASC}

Core Skills for the CASC (Woollard 2016) gives practical advice for trainees on how to prepare thoroughly for the CASC. Many course organisers

\section{BOX 1 Content of the MRCPsych written} examinations

\section{MRCPsych Paper A}

- Behavioural science and sociocultural psychiatry

- Human development

- Basic neurosciences

- Clinical psychopharmacology

- Classification and assessment in psychiatry

MRCPsych Paper B

- Organisation and delivery of psychiatric services

- General adult psychiatry

- Old age psychiatry

- Psychotherapy

- Child and adolescent psychiatry

- Substance misuse/addictions

- Forensic psychiatry

- Psychiatry of learning disability

- Critical review 
incorporate mock CASCs as part of their training programme. For maximum benefit these should take place near to exam sittings yet allow sufficient time for trainees to refine their skills if required. Organising mock CASCs can be time consuming, labour intensive and expensive.

Mock CASCs need an adequately sized venue with a separate space for trainees to register and receive feedback. Stations should be separated from each other (ideally by large screens) and contain a desk and chairs for the examiner, simulated patient and trainee. Importantly, mock CASCs require a pool of suitable examiners and simulated patients. Ideally, examiners should be consultant psychiatrists with experience of examining and/or an interest in medical education. Simulated patients can be sourced from professional acting companies that specialise in medical student/trainee exams; simulated patients introduce standardisation to the CASCs, allow trainees to be examined without fear of upsetting genuine patients (Barrows 1995) and can be sourced to cover specific areas of the curriculum. If possible, patients and carers should be involved in the development of mock CASC stations; the actors might include patients and (as does the MRCPsych itself) should include people with intellectual disabilities (Soni 2014). The mock CASC should be modelled on the two-circuit exam adopted by the College. The first circuit consists of eight individual stations (each lasting 7 minutes with 1 minute's reading time) and the second circuit consists of four linked stations (each lasting 10 minutes with 2 minutes' reading time).

Feedback is an integral and important component of the mock CASC. It should focus on performance, use non-judgemental language, emphasise positive aspects of performance and suggest areas for improvement (Shrivastava 2014). Too many negative comments can instil defeatism and should be avoided, particularly close to the MRCPsych itself. However, if an examiner has serious concerns about a trainee's competency, they have a duty to communicate this to both the trainee and the trainee's educational supervisor. The mock CASC in Birmingham's MRCPsych course offers trainees written feedback about their performance at each station as well as verbal feedback from each examiner and simulated patient.

\section{Online learning}

The use of internet-based learning is becoming increasingly prevalent in medical education (Cook 2008). Trainees are generally familiar with and comfortable using the internet, and online portfolios are now widely used. Trainees may find online resources particularly useful during exam preparation as they are accessible from any location and can be revisited as many times as required.

\section{Online modules}

The College has developed its own eLearning resource called Trainees Online (TrOn, at http:// tron.rcpsych.ac.uk), after recognising that trainees were preparing for the MRCPsych using websites not subject to quality control (Burn 2015). TrOn launched in 2014 and follows the popular format of CPD Online, the College's eLearning site for consultants (http://www.psychiatrycpd. co.uk). TrOn provides interactive online modules for trainees to complete, alongside links to the MRCPsych syllabus and the examination pages on the RCPsych website. To date, over 25 basic science modules are available on the website, and more than 60 further modules have been commissioned (including 30 covering the critical review and clinical areas of the syllabus). Modules are mostly written by post-membership trainees, and are published after being extensively qualitycontrolled, reviewed and checked against the MRCPsych syllabus.

Birmingham's MRCPsych course is also designing its own series of online modules and, if successful, these could be used to replace some of the didactic lectures on the course. These modules will be hosted on a dedicated website and trainees will be able to access them as many times as they wish while enrolled on the course; this releases more time at the end of the course to focus on leadership/management skills and research.

\section{Other online resources}

In addition to online teaching modules there is a variety of other online resources available to trainees preparing for the MRCPsych. Examples of these are listed in Box 2 and they include lecture notes (covering aspects of the MRCPsych syllabus) and databases of practice MCQs and EMIs. These resources are not affiliated to, or approved by, the Royal College of Psychiatrists and in many cases there is a cost attached to accessing their content (although some can be accessed for free).

\section{Advantages and disadvantages of online learning}

Online modules have been shown to increase knowledge, confidence and application of skills (Ruchter 2012). They are also flexible and their content can be tailored to the needs of individual learners (Cook 2008). Online learning, however, has potential disadvantages. First, modules require set-up and running costs, which can be considerable (Cook 2007). Second, technical 
BOX 2 Online resources available for trainees preparing for the MRCPsych ${ }^{a}$

- The Birmingham Course ${ }^{\mathrm{b}}$ (www.

birminghamcourseonline.co.uk)

- BMJ OnExamination (http://www.onexamination.com/ psychiatry)

- MRCPsychmentor (mrcpsychmentor.com)

- SPMM Course (http://spmmcourse.com)

- Superego Café (www.superegocafe.com)

- Trickcyclists.co.uk (www.trickcyclists.co.uk)

a. These resources are not affiliated to, or approved by, the Royal College of Psychiatrists.

b. This course is not related to the Birmingham-based

MRCPsych course for core trainees discussed in this article.

difficulties can affect learning and cause learners to disengage. Third, unless online modules are peer reviewed and appropriately supervised, trainees may feel lost within their content. If online resources are accessible, easy to use and perceived by trainees to be helpful in their exam preparation, they are more likely to be frequently utilised. There is also evidence that trainees are more likely to accept online learning if it fits in with their expectations and/or offers a perceived advantage over traditional teaching methods (Wong 2010).

\section{Patient involvement}

The Keogh Report on the quality of care in National Health Service (NHS) hospitals recommends that professionals develop partnerships with patients in the planning, delivery and evaluation of healthcare (Keogh 2013). It has been argued that these relationships should also therefore form the foundation of psychiatric training (Tew 2004). Although patients have long contributed to medical training through so-called 'bedside teaching', this is a passive role that fails to acknowledge patients as experts and a valuable 'untapped resource' (Dimambro 2009). Since Evans \& Seabrook (1994) highlighted that patients were keen to have a more active role in medical education, there has been a growing consensus that their participation in all areas of psychiatric training should be encouraged (Higgins 2011). Patient involvement in core psychiatric training was made mandatory in June 2005, with training schemes jeopardising their College accreditation if they are unable to demonstrate meaningful involvement (Fadden 2005).

There have been several pilot studies confirming the advantages of patient-led sessions (Ikkos
2003; Haeney 2007). Such sessions benefit trainees by challenging negative attitudes and raising awareness of the 'patient journey'; they also benefit patients by empowering them and boosting their self-esteem (Repper 2007). Despite this, some trainees still resist the involvement of patients in their training; their reservations relate primarily to issues of confidentiality and patients' 'over-involvement' (Dimambro 2009). Patientled sessions also require significant planning, supervision and financial cost (Dimambro 2009).

A survey of psychiatric trainees in the West Midlands indicated that $82 \%$ would prefer patients/carers to be involved in MRCPsych courses by sharing personal experiences and 70\% by providing feedback about skills and attitudes (Narula 2008). Birmingham's MRCPsych course therefore involves patients/carers in two distinct ways. First, it runs patient/carer workshops that punctuate all 3 years of the course. These sessions draw on patients' own experiences to generate group discussion about relevant topics, such as being detained under the Mental Health Act. Facilitating these workshops can be emotionally demanding for patients and carers, so they require careful planning and the patients/carers need access to debriefing (Fadden 2005). Second, patients and carers are involved in assessing trainees during communication skills and CASC practice sessions. In year 1 of the course, trainees receive feedback from patients or carers after completing a filmed consultation with a simulated patient. During years 2 and 3 they also receive feedback from patients/carers after practising CASC stations under supervision.

\section{Workplace-based assessments (WPBAs)}

The current competency-based curricula and workplace-based assessments (WPBAs) were introduced by the College in 2007. WPBAs were designed to support the annual review of competence progression (ARCP) process by facilitating a multidimensional evaluation of a trainee's longer-term performance (Brown 2006) and are one of the main methods of ensuring that doctors are progressing satisfactorily through their training. WPBAs should also identify underperforming trainees so that they can receive constructive feedback and improve their performance accordingly. However, it has become clear that a significant number of trainees who do well in WPBAs persistently fail the CASC (Sikdar 2010). Research suggests that negative attitudes have undermined the effectiveness of WPBAs (Menon 2012), that the quality and availability of assessor training are variable and that trainees' 
perceptions of WPBAs are mixed (Simmons 2013). The use of untrained and non-medical assessors has also been criticised: for example in one survey of non-medical assessors, only $44 \%$ felt comfortable conducting WPBAs and none had been trained to do so (Gangaram 2012).

To maximise the potential of WPBAs to assist trainees in passing the MRCPsych, trainees must receive direct and relevant feedback on their clinical work (Brown 2006). It is therefore important that assessors follow the seven basic requirements of effective performance feedback (Brown 2009) (Box 3). Although there is no absolute requirement for trainees to gain feedback from patients, consideration also needs to be given to this. Underperforming trainees in particular may wish to collect patient feedback and share it with their educational and clinical supervisors in order to develop their clinical skills.

\section{Recognising communication skills deficits early}

For early identification of trainees who have deficits in communication skills, Birmingham's MRCPsych course has implemented a six-station assessment of interview skills at the end of year 1 . Each station lasts 7 minutes with 2 minutes' preparation time and 5 minutes' face-to-face feedback from each assessor. Trainees also receive written feedback about their performance using a modified version of the Calgary Cambridge marking scheme (Kurtz 2004). The Calgary Cambridge assessment is a freely available, well used and validated assessment tool developed by educators of general practitioners and used widely to teach communication skills. We found the full-format version quite time consuming to populate during the six-station assessment, so we condensed several of the feedback domains and added descriptive Likert scales to ensure that assessors could complete the mark sheets in the allotted time. Although the sample size in our initial

\section{BOX 3 Seven criteria for effective performance feedback}

Performance feedback should be:

1 for the trainee's benefit and not solicited or imposed

2 timely

3 specific

4 descriptive and not evaluative

5 accurate

6 not embarrassing

7 relevant (unpublished) pilot was small, there was evidence of a correlation between trainees who performed least well in the interview skills assessment and those who obtained the lowest-scoring WPBAs at ARCP. Trainees are therefore encouraged to integrate feedback about their communication skills into their personal development plans and to share any areas of need with their educational supervisors.

\section{Supporting international medical graduates}

There is clear evidence that, on average, international medical graduates (IMGs) underperform on clinical skills exams compared with their UK counterparts (Oyebode 2007). IMGs are also less likely to obtain satisfactory ARCP outcomes compared with doctors in postgraduate training for a medical specialty or general practice in the UK (Tiffin 2014) and this holds true for other medical specialties (Bessant 2006; Watmough 2011). Although the reasons for this are likely to be multifactorial, several possible explanations have been suggested (Box 4) (Slowther 2012). Refugee doctors have been identified as being at a particular disadvantage (Cohn 2006).

To support IMGs, Dr Wendy Burn, the College's Dean, convened a scoping group to investigate these difficulties. An Associate Dean for IMGs has been appointed and an inaugural IMG conference was held in 2014 (Al-Taiar 2014). Various external organisations also specifically support IMGs; these include the UK divisions of the British Indian Psychiatric Association, the British Pakistani Psychiatrists Association, the British Arab Psychiatrists Association, the Hellenic Psychiatric Association and the European Federation of

BOX 4 Factors affecting the examination performance of international medical graduates

- Differences in the ethical and legal frameworks of practising medicine in the UK and overseas

- Differences in the model of the doctor-patient relationship

- Differences in workplace hierarchies and interprofessional relationships

- Differences in ways of interacting and assertiveness

- Social and cultural isolation

- Difficulties understanding accents and colloquialisms

- Difficulties communicating sensitive issues

- Reduced understanding of roles and multiprofessional settings

- Visa applications and job-hunting 
Psychiatric Trainees. Some of these organisations offer their own training and educational activities. The College also has a Diaspora Committee, which has published its first newsletter (Wessely 2015).

We recommend that a clear induction meeting takes place between clinical supervisors and IMGs and that IMGs are alerted to the GMC's Good Medical Practice (www.gmc-uk.org/guidance/ index.asp) and to areas that we know may cause them difficulties (Box 4).

Mentorship can be of particular benefit to IMGs, and schools of psychiatry should have clear protocols for its implementation. The College's Psychiatrists' Support Service provides information on coaching and mentoring, as well as support on dealing with exams (www.rcpsych.ac.uk/ workinpsychiatry/psychiatristssupportservice. aspx).

In many cases an IMG's first language is not English; some use English only at work, which might mean that during clinical interviews they are silently translating the patient's words into their own language. Although this may be manageable in the workplace, it is likely to be a significant disadvantage under exam conditions. In addition, if trainees are only speaking English while at work, to patients and colleagues, this may restrict the speed at which they develop their skills. IMGs should therefore consider enrolling on external communication skills courses and listening to English-language television and radio stations wherever possible. The filming of consultations is also a well-recognised method of enhancing communication skills (Nilsen 2005), allowing trainees to reflect on their 'annoying habits' and giving them an opportunity to make positive changes. Observed clinical encounters may be particularly helpful for trainees who suffer performance anxiety and/or continue to perform poorly despite feedback from WPBAs. It is widely recommended that all trainees preparing for the MRCPsych join a study group with their peers.

We hope that schools of psychiatry will develop their own IMG champions who can work locally to help disseminate knowledge of available resources to help these students, keep clinical supervisors informed of developments and maximise the potential for IMGs to increase their success rate on exams. We need to keep in mind that failing an exam can be a very expensive experience.

\section{Conclusions}

Recent changes to the MRCPsych examinations pose challenges for those involved in designing and coordinating psychiatric training, particularly in terms of tailoring the content of MRCPsych courses to those at different stages of the assessment process. It is therefore imperative that these courses are evaluated thoroughly so that they continue to support exam preparation in an effective and efficient manner. Preparing materials for MRCPsych courses, mock exams and revision courses is time consuming and labour intensive. It is therefore advisable for course organisers to recruit honorary clinical teachers and a pool of senior doctors who can assist with assessment. The involvement of patients/carers in MRCPsych courses is mandatory, but care needs to be taken to ensure that their contribution is worthwhile and not tokenistic. MRCPsych courses should also be willing to adapt to trainees' needs and to consider the introduction of online learning to run alongside the College's TrOn initiative. It is recognised that some trainees do well in WPBAs yet repeatedly fail the CASC component of the MRCPsych; it is therefore crucial for educators to be trained in delivering effective performance feedback to psychiatrists at all stages of training. This seems to be especially important for IMGs.

\section{References}

Al-Taiar H, Menzies A (2014) Report on the RCPsych IMG Conference 2014. Royal College of Psychiatrists.

Barrows HS (1995) How to Design a Problem-Based Curriculum for the Pre-Clinical Years. Springer.

Berrisford GS, Vassilas CA (2010) MRCPsych courses: the national picture. Psychiatrist, 34: 301-3.

Bessant R, Bessant D, Chesser A, et al (2006) Analysis of predictors of success in the MRCP (UK) PACES examination in candidates attending a revision course. Postgraduate Medical Journal, 694: 145-9.

Bowie P (2015) Papers A \& B Marking Scheme. Royal College of Psychiatrists (http://www.rcpsych.ac.uk/traininpsychiatry/examinations/ examinationstab/mrcpsychpapera/writtenpapersmarkingscheme.aspx). Accessed 26 February 2016

Brown N, Doshi M (2006) Assessing professional and clinical competence: the way forward. Advances in Psychiatric Treatment, 12: 81-9.

Brown N, Cooke L (2009) Giving effective feedback to psychiatric trainees. Advances in Psychiatric Treatment, 15: 123-8.

Burn W, Bowie P (2014a) Changes to the MRCPsych written papers and transitional arrangements. Royal College of Psychiatrists (http:// www.rcpsych.ac.uk/traininpsychiatry/examinations/resourcestab/ changestowrittenpapers.aspx). Accessed 26 February 2016.

Burn W (2014b) Standards for a College Approved Academic Course. Royal College of Psychiatrists (http://www.rcpsych.ac.uk/pdf/Standards_ for_a_College_Approved_Academic_Course_February_2014.pdf).

Burn W (2015) Our goals. Trainees Online, Royal College of Psychiatrists (http://tron.rcpsych.ac.uk/abouttron/ourgoals.aspx). Accessed 26 Feb 2016.

Cohn S, Alenya J, Murray K, et al (2006) Experiences and expectations of refugee doctors: qualitative study. British Journal of Psychiatry, 189: 74-8.

Cook DA (2007) Web-based learning: pros, cons and controversies. Medical Education, 7: 37-42.

Cook DA, Levinson AJ, Garside S, et al (2008) Internet-based learning in the health professions: a meta-analysis. JAMA, 300: 1181-96.

Dimambro BJ, Doody GA (2009) Service user organisations: an untapped teaching resource. Psychiatric Bulletin, 33: 72-4.
MCO answers

$1 d \quad 2 b \quad 3 c \quad 4 c \quad 5 a$ 
Evans T, Seabrook M (1994) Patient involvement in medical education. British Journal of General Practice, 44: 479-80.

Fadden G, Shooter M, Holsgrove G (2005) Involving carers and service users in the training of psychiatrists. Psychiatric Bulletin, 29: 270-4.

Gangaram P, Halder N, Kumar P (2012) Survey of non-medical professionals on the use of workplace-based assessments. Psychiatrist, 36: 151-4.

George S (2003) Extended matching items (EMls): solving the conundrum. Psychiatric Bulletin, 27: 230-2.

Haeney O, Moholkar R, Taylor N, et al (2007) Service user involvement in psychiatric training: a practical perspective. Psychiatric Bulletin, 31 : 312-4.

Higgins A, Maguire G, Watts M, et al (2011) Service user involvement in mental health practitioner education in Ireland. Journal of Psychiatric and Mental Health Nursing, 18: 519-25.

Ikkos G (2003) Engaging patients as teachers of clinical interview skills. Psychiatric Bulletin, 27: 312-5.

Keogh B (2013) Review into the Quality of Care and Treatment Provided by 14 Hospital Trusts in England: Overview Report. NHS

Kurtz S, Silverman J, Draper J (2004) Teaching and Learning Communication Skills in Medicine (2nd edn). Radcliffe Publishing.

McCoubrie P (2004) Improving the fairness of multiple-questions: a literature review. Medical Teacher, 26: 709-12.

Menon S, Winston M, Sullivan G (2012) Workplace-based assessments: attitudes and perceptions among consultant trainers and comparison with those of trainees. Psychiatrist, 36: 16-24.

Narula A, Furlong E, Fung NK (2008) Trainees' views on service user and carer involvement in training: a perspective from the West Midlands. Psychiatric Bulletin, 32: 197-8.

Newbie DI, Entwistle NJ (1986) Learning styles and approaches: implications for medical education. Medical Education, 20: 162-75.

Nilsen S, Baerheim A (2005) Feedback on video recorded consultations in medical teaching: why students loathe and love it - a focus group based qualitative study. BMC Medical Education, 19: 28.

Oyebode F, Furlong E (2007) MRCPsych examinations: cumulative results 1997-2002. Psychiatric Bulletin, 31: 61-4.

Repper J, Breeze J (2007) A review of the literature on user and carer involvement in the training and education of health professionals. International Journal of Nursing Studies, 44: 511-9.

Royal College of Psychiatrists (2010) A Competency Based Curriculum for Specialist Core Training in Psychiatry. Royal College of Psychiatrists.

Ruchter V, Lindsey C, Graham M, et al (2012) Use of online modules to enhance knowledge and skills application during an introductory pharmacy practice experience. American Journal of Pharmaceutical Education, 76: 69

Schuwirth LW, van der Vleuten CP (2004a) Different written assessment methods: what can be said about their strengths and weaknesses? Medical Education, 38: 974-9.

Schuwirth LW (2004b) Assessing medical competence: finding the right answers. Clinical Teacher, 1: 14-8.

Shrivastava SR, Shrivastava PS, Ramasamy J (2014) Effective feedback: an indispensable tool for improvement in quality of medical education. Journal of Pedagogic Development, 4: 12-20.

Sikdar S (2010) WPBA or CASC/OSCE: where is it going wrong? Psychiatrist, 34: 72-3.

Simmons M (2013) How are workplace-based assessments viewed by UK psychiatry trainees? Psychiatria Danubina, 25: 182-4.

Slowther A, Lewando-Hundt GA, Purkis J (2012) Experiences of nonUK-qualified doctors working within the UK regulatory framework: a qualitative study. Journal of the Royal Society of Medicine, 105: 157-65.

Soni S, Hall I, Doulton P, et al (2014) Involving people with intellectual disabilities in the assessment of healthcare professionals. Advances in Mental Health and Intellectual Disabilities, 8: 362-9.

Swift G (2016) Are journal clubs useful in teaching psychiatry? BJPsych Advances, 22: 203-210.

Tew J, Gell C, Foster S (2004) Learning from Experience: Involving Service Users and Carers in Mental Health Education and Training. Mental Health in Higher Education, National Institute for Mental Health in England (West Midlands), Trent Workforce Development Confederation.

Tiffin PA, Illing J, Kasim AS, et al (2014) Annual Review of Competence Progression (ARCP) performance of doctors who passed Professional and Linguistic Assessments Board (PLAB) tests compared with UK medical graduates: national data linkage study. BMJ, 348: 1756-833.

Watmough S, Bowhay A (2011) An evaluation of the impact of country of primary medical qualification on performance in the UK Royal College of Anaesthetists' examinations. Medical Teacher, 33: 938-40.

Vassilas CA, Berrisford GS (2011) Running an MRCPsych course. Advances in Psychiatric Treatment, 17: 72-80.

Wessely S (2015) College News: Launch of Diaspora Newsletter. RCPsych eNewsletter - June 2015. Royal College of Psychiatrists (http://www. rcpsych.ac.uk/usefulresources/rcpsychenewsletters/enewsletters2015/ june2015.aspx).

Woollard J, Jenkinson J (2016) Core Skills for the CASC. RCPsych Publications, in press

Wong G, Greenhalgh T, Pawson R (2010) Internet-based medical education: a realist review of what works, for whom and in what circumstances. BMC Medical Education, 10: 1-10.

\author{
MCOs \\ Select the single best option for each question stem \\ 1 The number of attempts candidates have \\ to pass a written paper of the MRCPsych \\ examinations is: \\ a two \\ b four \\ c five \\ d six \\ e unlimited.
}

2 Paper A of the MRCPsych exam includes the following topic:

a general adult psychiatry

b human development

c old age psychiatry $d$ the organisation and delivery of services

e critical review.

3 The seven basic requirements of effective performance feedback do not include:

a for the trainee's benefit

b solicited not imposed

c general not specific

d accurate

e not embarrassing. d mandatory course organiser

e regular trainee feedback.

5 Patient and carer involvement in teaching psychiatric trainees:

a requires significant planning

b was made mandatory in 2010

c is regarded negatively by trainees

d should be avoided owing to concerns about confidentiality

$\mathrm{e}$ is seen as tokenistic.

4 The College standards for an MRCPsych course do not include:

a patient and carer involvement

b adequate administrative support

c running a mock CASC 